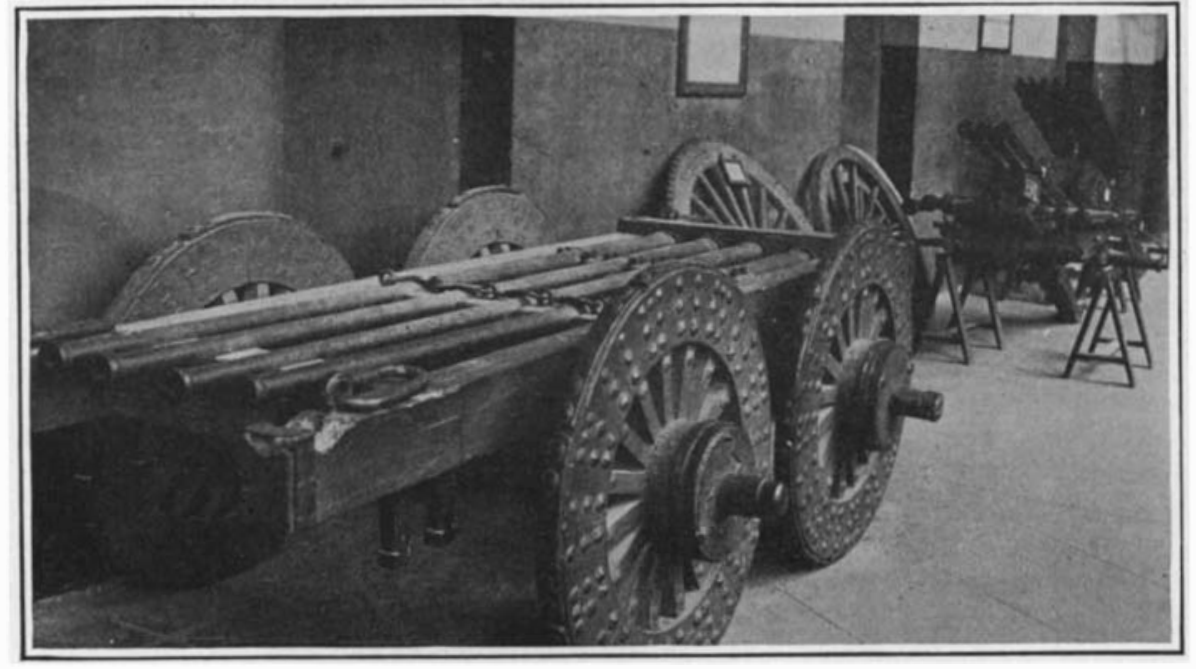

Chinese machine-gun which was produced about 1300 A. D.

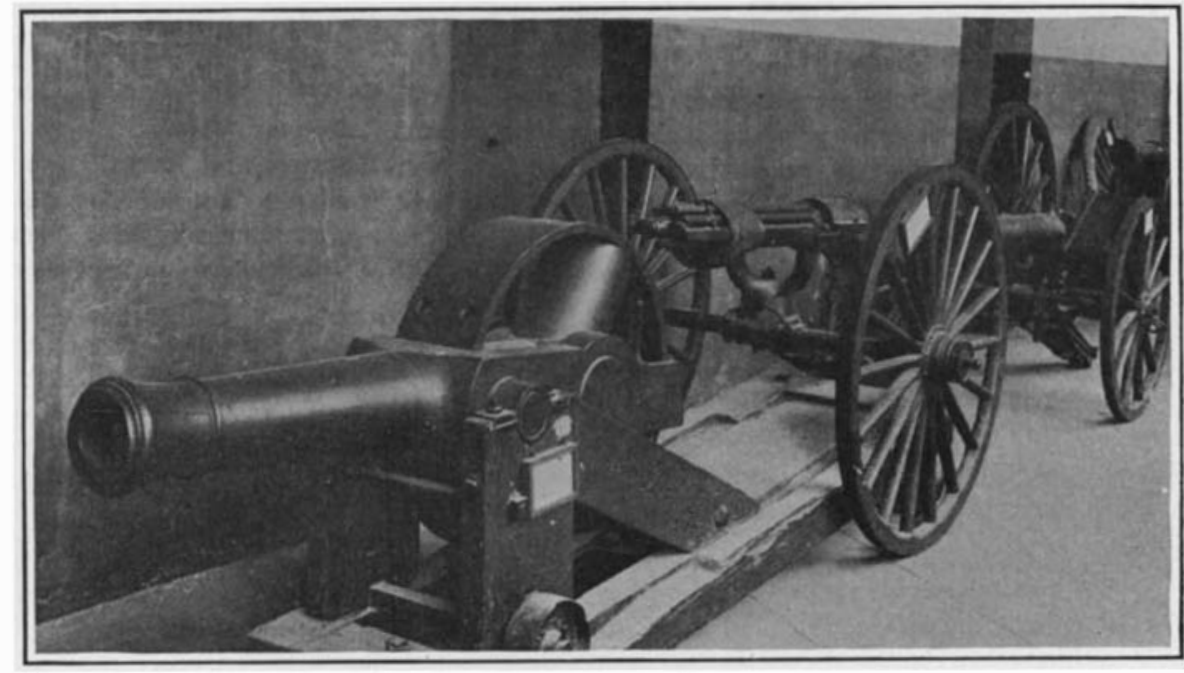

American revolving cannon used in the war of 1812

\title{
The Machine-Gun and Its Development
}

By Neal Truslow. Our Correspondent with the French Army at the Front

SO far the Germans have proved themselves the mas-

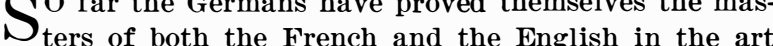
of making for to-day the weapons of to-morrow. Instead of seeking to adapt new circumstances to old theories, they have changed their theories to meet the circumstances, and that is why they are able to make such a stubborn resistance. So firm is the German belief in machine-guns that they have nearly discarded he infes. This, of course, is a shock, not only to melita to military tradition, but to the popular conception of the soldier. Sloping rifles and gleaming bayonets are the fixed symbols of the army, and it is difficult, if not impossible, to imagine our soldier going into action with several yards of iron pipes under his arm. Yet statistics show that one machine-gun properly placed can hold a battalion. Twenty-one Germans are known to have held 1,100 yards of trenches for five months in a field, south of Soissons; several attacks were made against them without effect.

We should realize that a machine-gun, in competent hands, is accurate with a deadly accuracy. Tests against picked shots have shown that one machine-gun will make more hits than 50 marksmen, as there are rarely 50 marksmen in a regiment of 1,000 men. We may safely say that as a target hitter, a machine-gun is equal to a regiment.

The development of this most effective of the weapons has been very interesting, and much money and time spent in perfecting it. Few of us realize that the machine-guns of a primitive kind were found in the early history of gunpowder artillery.

In 1382 , the army at Ghent put 200 chars de canon in the field, a number of barrels mounted on twowheeled carriages, garnished with pikes and scytheblades. In 1411 the Burgundian Army is said to have had 2,000 of these weapons. Louis the Twelfth had a machine-gun which fired 50 shots at one round.

And about this time, in Italy, we read of a more curious than useful weapon of four barrels, which was fired from the back of a donkey. Yet this is not strange, when we consider the work of a Canadian machine-gun crew which reached the trenches recently reduced to Lieutenant Cambell and Private Vincent. In default of a base, Lieutenant Cambell set up the machine-gun on the broad back of Private Vincent, and fired continuously until Lieutenant Cambell was wounded. Private Vincent then cut away the catridge wert, abandoning the tiripod and dragsed the gun away belt, abandoning the tripod and dragged the gun away to safety.

The ribaudequin Chinois captured from the Chinese by the French in 1860 is probably the earliest type of machine-gun known. Those who have knowledge of the Chinese believe that this model was produced somewhere about the beginning of the fourteenth century. It consists of a very heavy truck reinforced with iron on which is mounted four iron barrels, 9 feet long. Since these barrels were practically stationary, they must have been used for a volley of grape or case shot

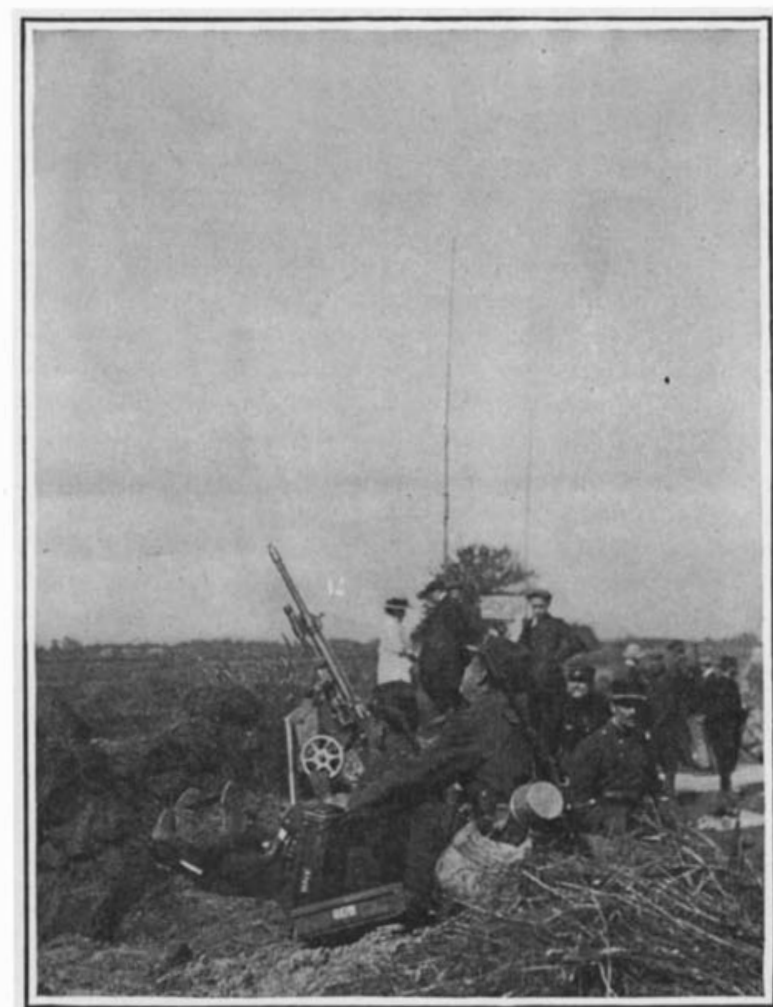

Using a machine-gun against air-craft

at very close range. They were fired simultaneously by a trail of powder leading to each fuse hole.

The next weapon important in the development of machine-guns was the Danish nine-barrel gun mounted in sets of three on a two-wheeled carriage. This proved of great value, and was effective in that one set of barrels could always be held in reserve, while the other was loaded. It was about this time that America startled the English with their bronze revolving cannon, capable of firing three charges in quick succession, this gun was very popular in the War of 1812 , and doubtless was responsible for some of our sensational sea victories.

A satisfactory machine-gun was not found until breech-loading had been discovered. In 1860, Richard Gatling produced a gun which proved most successful in both the Civil and the Spanish wars. It was distinctly an infantry type gun. The ten barrels of which were set around an axis and fired in turn as the revolving mechanism operated by a crank brought them into position. Cartridges were arranged in a drum, and as one drum emptied another was put in its place. Experimental Gatlings were constructed, which could give a thousand shots per minute. This gun had a long range, and was used most effectively. But a grave disadvantage was the impossibility of avoiding frequent jams. Its weight and the necessity of operating the breech mechanism by hand were also serious objections. Other machine-guns of the hand-operated type rapidly followed, such as the Reffye, 1866, which weighed 2,710 pounds. The Requa battery, an artillery type, was tried by the United States Navy. The Hotchkiss, the Gardner, and numerous others had a vogue. But, next to the Gatling, the most important was the Nordenfeldt, which was designed, principally, for navy use, at the time when torpedo boats were beginning to be regarded as dangerous antagonists.

Hitherto we have been dealing with the more or less primitive type of guns. Possibly the great change in modern warfare has been due, largely, to the development of the modern automatic machine-gun. The loading, firing, extracting, and ejecting are all performed by the gun itself, either by the recoil of the barrel, the recoil of the breech or by a small portion of the gases of the explosion being allowed to escape through a minute opening in the barrel, near the muzzle.

Some 60 years ago, an American, Henry Bessemer, proposed and patented, in 1854, the system of using a portion of the gas for working the breech mechanism. automatic gun of practical value, of the recoil system, which was adopted by the British Government in 1889. In his gun, the barrel and breech casing are firmly fastened together. The former contains the barrel and water jacket used to keep down the high temperature caused by rapid firing which, by the action of a sliding valve, allows the escape of steam and (1) front and rear bearing, which allows of its sliding in (Concluded on page 473)

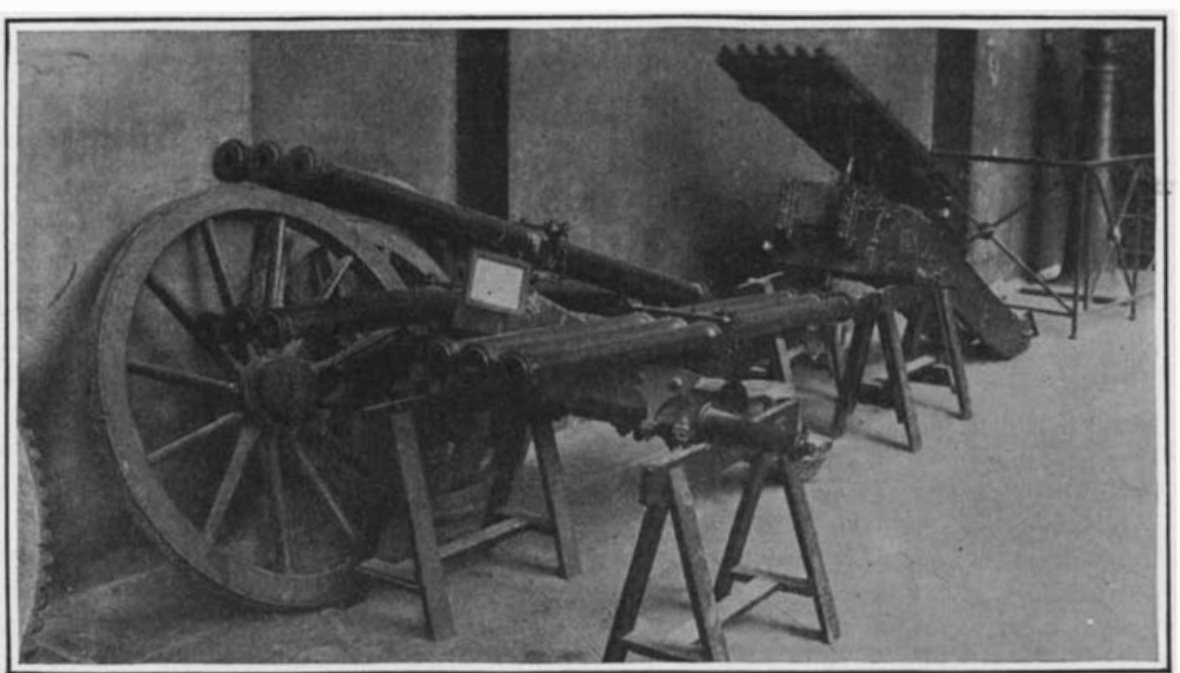

Danish 9-barrel gun of 1868 that fired 40 rounds per minute

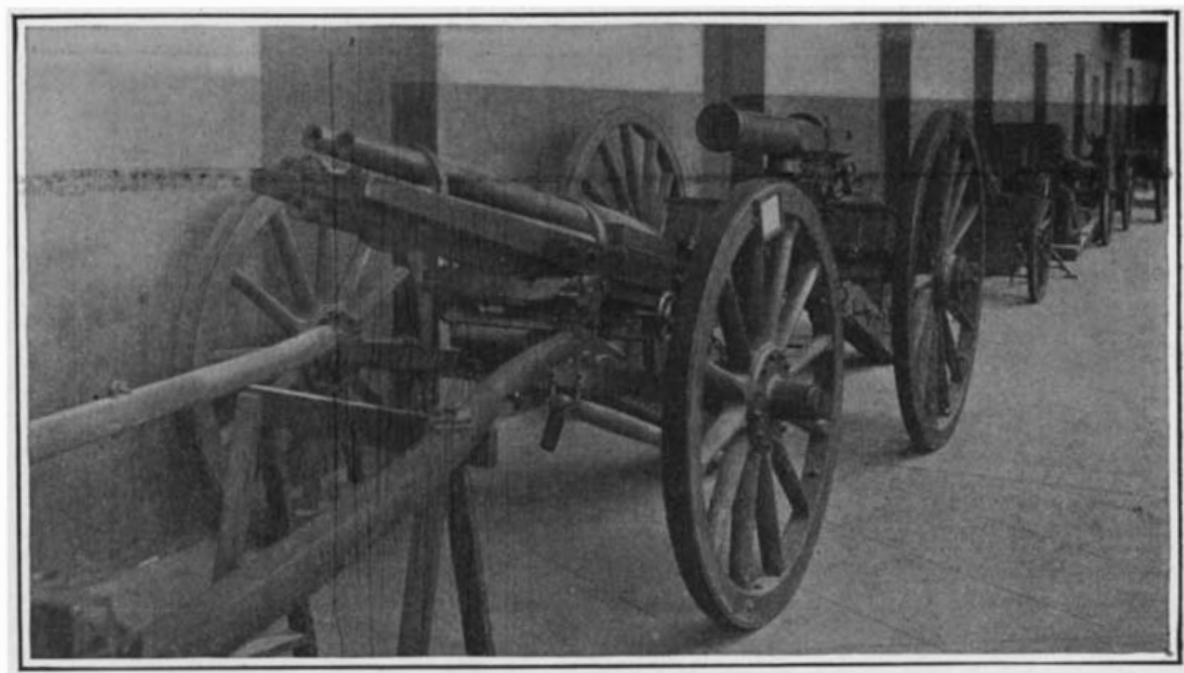

Revolving cannon of 1868, breech loading, and firing 60 shots per minute 
The Machine-Gun and Its Development

(Concluded from page 464 .)

recoil, the breach casing is a rectangular box containing lock and firing mechanism. At the rear it has two handles by which the gun is directed.

In the Maxim, the gun which is now being used by both the English and the Germans, the total recoil of the barrel is about 1 inch. The side plates and lock all recoil together about $1 / 4$ of an inch without any disturbance of the lock, and by the time this short travel is complete the bullet has left the muzzle. The force of the recoil then operates the mechanism which opens the breech, ejects the cartridge, a spring expands, which when relieved closes the breech after taking a new shell from the cartridge belt and placing it in readiness to fire.

The Maxim gun is light and easily handled, weighing from 50 to 60 pounds, and fires from 450 to 600 rounds per minute. The cartridge belt contains 250 rounds, and is provided with a catch which makes it possible to add any number of belts while the gun is in number of belts while the gun is in
operation. These belts are loaded back operation. These belts are loaded back
of the line by machinery. The greatest objection to this gun seems to be that, a the end of 300 to 400 rounds, the water in the jacket boils, throwing off quantities of steam, disclosing the position of the gun. The Germans ingeniously use a tube to carry off this steam. There is
also the frequent difficulty of the 5 pints of water contained in the jacket boiling away, leaving the gun with absolutely no radiation

The Hotchkiss type, which has been adopted by the French Army, depends for its action on the use of a small portion of gas from the explosion itself The barrel is attached firmly to the frame. The latter containing the breech and firing mechanism under the barrel, and, communicating with it by a post, is and the bullet has passed the post, a portion of the gas of the explosion passes into the cylinder and drives back the piston contained in it, a lug on the underside of which compresses a spring, which, when the trigger is pulled, drives back the piston again. The reciprocating motion of the piston performs all the process of loading and firing the gun. The action being continuous as long as the trigger is held. Cartridges are placed in feeding strins, containing 50 rounds each; when the last shot has been fired, for a fresh strip to be inserted.

'The Hotchkiss has many advantages, its working parts are very simple and easily repaired, it is light, weighing 53 pounds, and fires 500 to 600 tin.es per minute. No water is required for the radiation of the heat, generated by rapid fire, as that is facilitated by the radiation which consists of rings on the barrel close to the breech offering an increased surface to the air.

The Colt automatic gun, adopted by the American and English armies, weigh 40 pounds, and is extremely simple and compact. Its operation is similar to the Hotchkiss, using the gases through a post near the muzzle to operate a piston. But its novel feature is that the air is compressed in the rear of the piston as it is driven back, passing through a ube to the breech, thus a puff of air is blown through the barrel after each shot, cleaning out foul and unconsumed powder and assisting to a considerable extent in keeping down the temperature of the barrel. The gun will fire 100 times per minute and its compactness makes it very portable.

In talking with a well-known genera at the Ecole Militaire, the other day, he said: "The English hold their trenches with the infantry, the French with artilery, but the Germans with machineguns." There is, no doubt, that the contribution which this war is destined to make to the science of warfare lies in the direction of the development of the ma chine-gun. I am in a position to know that the Germans started the war with 50,000 machine-guns, and, while that num- ber was approximately accurate then, the number is enormously increased to-day. Machine-guns are cheap. The parts are easily duplicated, and the general claims hat it is just as easy to make a serviceable machine-gun as a rifle. The Allies have increased the number of their machine-guns, but the Germans have done the same. Now, they are going further, they are virtually substituting men armed with machine-guns for the old-fashioned infantry armed with rifles. They are holding their vast line with a very small number of men armed with machine-guns protected with concrete work and wire entanglements. Their infantry is only brought up in emergencies, and is not constantly exposed to bombardment. Their machine-guns are sheltered by steel plates, and can only be put out of action y a direct hit with a high explosive shell. The Allies were soon to realize how much ground they had to make up in the matter of machine-guns, so in addition to the school of musketry and artillery both the French and the English have stablished the machine-gun school. It is a place of hard work and quick think-
ing. It would be inexpedient to dwell on ing. It would be inexpedient to dwell on
the nature of the work carried on at the the nature of the work carried on at the
school, but I may say that the school is in daily touch with every phase of machine-gun warfare at the front.

As far as the army in the field is concerned, the machine-gun is coming into ts own, both officers and men who came up for machine-gun training have thrown themselves with the utmost keenness into chine-gun has introduced

'The advantage of the increased firing power of the machine-gun is so obvious hat it need not be dwelt on. It has already been adopted in some foreign armies; every fourth man in the Brazilian
cavalry is, I believe, armed with one. It will be only a short time, I hope, until our National Guard will realize the importance of these weapons, and will be proprly drilled and equipped with this most effective of weapons of defense. No army can live before them. No strategy can outwit them.

Apparatus for Mechanical Administration of Anaesthetics Continued from page 471)

struction and mechanical principle to a vichy siphon. It consists of an air-tight, graduated glass container having a cap arranged with two valves. One valve is an inlet valve for air, similar to the valve permits air to enter but automatically prevents its escape. The other valve is an outlet valve to control the flow of anæsthetic forced out under the air pressure. This valve is so adjusted that the number of drops per minute discharged from the container may be accurately controlled. The air pressure ecessary to operate the device is obtained by means of a small rubber hand bulb similar to an atomizer bulb. This bulb is only used to charge the apparatus, after which it is removed just as in the case of a vehicle tire after it has been with the anæsthetic and charged with air in this way it is ready for use and will operate automatically until it is emptied. The anæsthetic is discharged through a long flexible tube to the face mask where it is diffused upon the gauze by.. means of multi-perforated tubes arhas to do is to place the mask upon the patient's face and turn the valve so that the requisite number of drops per minute are flowing to the mask. The rate of flow is observed through the glass sight feed on the cap.

The new apparatus affords a marked contrast with the conventional methods in use to-day for the administration of anæsthetics. The latter, it is said, are at the best exceedingly crude and, unless under the supervision of a professional anæsthetist, are more or less haphazard On the other hand of the best results. of applying anesthetics is at all times under control, although it will perform its

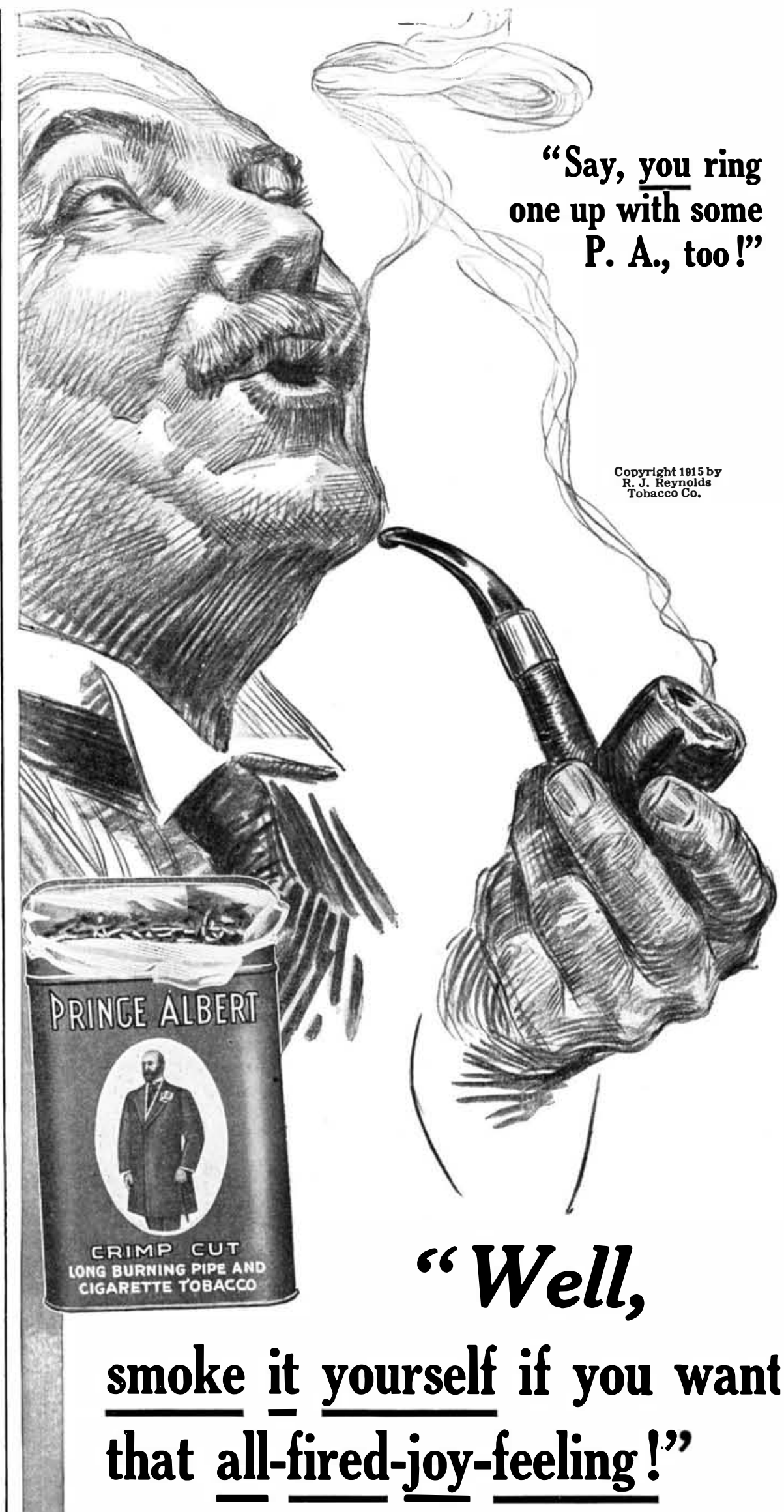

Prince Albert hands out more genuine happiness each puff-via jimmy pipe or makin's cigarette-finer flavor each puff and fresher fragrance each puff than you ever did dream would fall to your lot. The patented process fixes that-and cuts out bite and parch! From dawn's early light until turn-in-time you can bang away, man-like, because there isn't any flare-back in

\section{PRINGE ALBERT}

the national joy smoke

Don't you linger-longer-than-a-mighty-short-time about what you're going to do about this pipe-packing and makin's-material question. Because, men, you're losing fascinating fun and a bunch of contentment that will slide-into-your-system when you greet P. A. face-to-face!

Now, you set-sails and steer right to Port P. A. and swing swift and true with your party-pipe or some "papers" and it'll be fair weather for yours, coming and going! Go to the toppy red bag, at a nickel; or land on the tidy red tin for a dime; or pick the handsome pound and half-pound tin humidors. But of all the P. A. packages, you'll find that classy crystal-glass pound humidor what you need most! The sponge in the top keeps the friendly tobacco in such bang-up trim!

R. J. REYNOLDS TOBACCO CO., Winston-Salem, N. C. 